\title{
APOIO À IMPLANTAÇÃO DE UNIDADES DE CONSERVAÇÃO NA REGIÃO CENTRO-NORTE CATARINENSE ${ }^{1}$
}

\section{Support for the implementation of protected areas in the Center-North Catarinense Region \\ Apoyo a la implantación de unidades de conservación en la Región Centro-Norte Catarinense}

\author{
Rosemeri Carvalho Marenzi ${ }^{2}$ \\ Susana Beatriz da Costa da Cunha ${ }^{3}$ \\ Kariny Zanella Demessiano ${ }^{4}$ \\ Karoline L. Fendel ${ }^{4}$ \\ Lígia Padilha Novak ${ }^{4}$ \\ Mariela E. Soto Araya ${ }^{4}$
}

\begin{abstract}
RESUMO
A região do litoral centro-norte catarinense precisa despertar para a oportunidade e necessidade de implantação de unidades de conservação, pois poucas unidades foram criadas e a maioria inexistindo delimitação, regularização fundiária e adoção de infraestrutura e de mão de obra adequadas. Ainda, outros locais apresentam potencial e/ou necessidade de proteção, aumentando a quantidade e a qualidade de áreas protegidas. O processo que envolve desde a criação até a efetivação destas unidades é regido pelos Sistemas Nacional e Estadual de Unidades de Conservação. Portanto, exigindo conhecimento técnico-legal e procedimentos político-administrativos, sendo necessária assistência aos atores sociais interessados e envolvidos, entendendo que um adequado embasamento conceitual sobre o assunto, assim como o despertar para a participação dos atores sociais é uma forma de estimular e incentivar a consolidação do processo. Este Projeto atuou por meio da organização de banco de dados, da realização de reuniões e oficinas locais e da elaboração de listagem de problemas e de oportunidades observados em cada processo de atuação. As técnicas e estratégias utilizadas em cada processo variaram de acordo com as características dos mesmos e a fase em que se encontravam. Foram trabalhados oito processos de unidades de conservação, em cinco (5) municípios e tiveram trinta e cinco (35) instituições envolvidas entre órgãos públicos, organizações não governamentais e instituição de ensino, assim como dezoito (18) estudantes participantes, além de representantes da comunidade que participaram em diferentes momentos.
\end{abstract}

Palavras-chave: unidades de conservação; Parque do Atalaia; participação.

\begin{abstract}
The coastal region of the central-north catarinense must awake to the opportunity and need for deployment of protected areas, because few units were created and most of them were not demarcated, without land regularization and adoption of infrastructure and appropriate labour. Still, other places have potential and/or need for protection, increasing the quantity and quality of protected areas. The process involving the creation provided to the effectiveness of these units is governed by the National and State System of Protected Areas. Therefore, requiring technical-legal knowledge and political-administrative procedures and becoming necessary assistance to social actors concerned and involved, and an adequate conceptual
\end{abstract}

1 Pró-Reitoria de Pós-graduação, Pesquisa, Extensão e Cultura da Universidade do Vale do Itajaí (UNIVALI).

2 Doutora, UNIVALI, Rua Uruguai, 458, Centro, Itajaí, SC, CEP: 88302-202; email: merimarenzi@univali.br.

3 Especialista, Secretaria Municipal de Educação de Itajaí.

4 Bolsista de Extensão. 
basement on the subject, the awakening to the participation of actors is a way to stimulate and encourage the consolidation of the process. This project was served by the organization of a database, holding local meetings and workshops and preparing lists of problems and opportunities found in each case of action. The techniques and strategies used in each case varied according to the characteristics in the same stage where they were. The project worked in eight cases, in five (5) municipalities and had thirty-five (35) institutions involved among public bodies, non-governmental organizations and institutions of education, as well as eighteen (18) students participating, in addition to representatives of communities, who participated at different times.

Keywords: protected areas; Atalaia Park; participation.

\section{RESUMEN}

La región de la costa centro-norte catarinense necesita despertar para las oportunidades y la necesidad de la implantación de unidades de conservación, pues pocas unidades han sido creadas y la mayoría con delimitación inexistente, regularización agraria y adopción de infraestructura y de mano de obra adecuadas. Todavía, otros locales presentan potencial y/o necesidad de protección, aumentando la cantidad y la calidad de áreas de protección. El proceso que envuelve desde la creación hasta la consolidación de estas unidades es conducido por los Sistemas Nacional y Estadual de Conservación. Por lo tanto, exigiendo conocimiento técnico-legal y procedimientos político-administrativos, siendo necesario auxilio a los agentes sociales interesados y envueltos, entendiendo que un embasamiento conceptual adecuado sobre el tema, así como el despertar para la participación de los agentes sociales es una forma para estimular y para incentivar la consolidación del proceso. Este proyecto actuó por medio de la organización de la base de datos, de la realización de reuniones y talleres locales y de la elaboración del listado de problemas y de oportunidades observados en cada proceso de actuación. Las técnicas y las estrategias usadas en cada proceso varían de acuerdo con las características de cada cual y de la fase donde se encontraban. Ocho procesos de unidades de la conservación han sido trabajados, en cinco (5) ciudades y tuvieron treinta y cinco (35) instituciones envueltas entre los órganos públicos, organizaciones no gubernamentales y la institución de educación, así como dieciocho (18) estudiantes participantes, además de representantes de la comunidad que participaron en diversos momentos.

Palabras-clave: Áreas Protegidas; Parque del Atalaia; Participación.

Introdução

A beleza cênica e a biodiversidade associadas à descaracterização da paisagem e a especulação imobiliária no litoral centro-norte catarinense refletem a necessidade de medidas conservacionistas. Uma das medidas mais eficientes para a proteção da biodiversidade e manutenção dos ecossistemas é a criação e efetivação de Unidades de Conservação.

As Unidades de Conservação são áreas protegidas, delimitadas e instituídas legalmente, passando a ter um tratamento diferenciado de acordo com as suas categorias de manejo. A implantação destas, além do potencial de poder oferecer recreação ao ar livre, área para pesquisa, atividades de educação ambiental $e$ preservação de ecossistemas representativos e da biodiversidade existente, pode contribuir através da geração de empregos diretos e indiretos, esses últimos decorrentes da valorização da área do entorno da unidade (MARENZI, 2005).

Dentro desta perspectiva, muitos estados e cidades já criaram tradição no investimento com fins de implantação de unidades de conservação. A região centro-norte catarinense não contempla UCs estaduais ou federais, apesar de já contar com algumas unidades municipais, mas ainda precisa despertar para esta oportunidade e ao mesmo tempo necessidade essencial, uma vez que as unidades somente foram criadas no "papel", inexistindo delimitação, regularização fundiária e adoção de infraestrutura e de mão de obra necessárias para que se atinjam os objetivos da categoria de manejo.

Ainda, outros locais na região apresentam potencial e/ou necessidade de proteção, devendo ser incluídos no sistema de unidades 
de conservação, aumentando a quantidade e a qualidade de áreas protegidas.

O processo que envolve desde a criação até a efetivação dessas unidades é regido pelos Sistemas Nacional e Estadual de Unidades de Conservação - SNUC e SEUC (BRASIL, 2000; SANTA CATARINA, 2001). Portanto, exigindo conhecimento técnico-legal e procedimentos político-administrativos, se fazendo necessária assistência aos atores sociais interessados $e$ envolvidos, entendendo que um adequado embasamento conceitual sobre o assunto é uma forma de estimular e incentivar a consolidação do processo.

O Laboratório de Planejamento e Manejo de Unidades de Conservação (LPMUC) e o Laboratório de Geoprocessamento e Sensoriamento Remoto da UNIVALI já se encontram envolvidos com vários processos em andamento. Para Brito (2003) uma proteção sustentável e efetiva depende, em grande medida, de um forte envolvimento da comunidade, que deve começar no planejamento,e ser um elemento contínuo no regime de manejo. Portanto, para que a participação ocorra, atores sociais devem estar motivados e engajados, e para isto, variáveis como conhecimento, interesses e perspectivas devem nortear as estratégias de envolvimento.

No caso específico de implantação do Parque Municipal do Atalaia, a maioria dos atores sociais envolvidos no planejamento da unidade, reivindicou a criação do parque inserindo toda a morraria (93 ha), diferentemente da proposta da prefeitura (19 ha.), justificando que a área menor não será eficiente para conservação da biodiversidade local. Ainda, alegam à necessidade do estabelecimento de corredor ecológico, conectando este fragmento a outros remanescentes naturais (Praia Brava e Ressacada). Este fato denota o nível de entendimento dos atores em relação à vulnerabilidade frente à pressão antropogênica na fragmentação de habitats, demonstrando o resultado do processo participativo enfocado pelo LPMUC na etapa de capacitação.

No entanto, as atividades realizadas com este fim atendem demandas, sem o estabelecimento de um sistema planejado $e$ organizado, a fim de estimular e acompanhar o andamento dos processos, otimizando esforços, propiciando maior eficiência na assistência técnica e consolidando ações que resultem na efetivação de um número crescente de Unidades de Conservação.

Em 2007, foi aprovado o Projeto de Extensão Apoio à implantação de Unidades de Conservação na região centro-norte catarinense, cuja estratégia busca capacitar atores sociais e acompanhá-los no processo que envolve desde o planejamento até a efetivação de áreas protegidas.

Este trabalho, portanto, visa relatar a experiência de um ano de atividade do referido projeto, apresentando resultados obtidos de janeiro a dezembro de 2007.

\section{Metodologia}

Considerando que o projeto visou dar continuidade aos procedimentos em andamento, consolidando-os, a metodologia buscou organizar as atividades de forma a otimizá-las, sendo estabelecidas as seguintes atividades:

Etapa 1 - Organização de Banco de Dados em relação aos Processos por meio de pesquisa documental e bibliográfica, assim como entrevistas aos atores envolvidos, conforme Seixas (2005). Alguns resultados do banco de dados resultaram, em conjunto com levantamentos de campo, em diagnósticos ambientais.

Etapa 2 - Realização de reuniões e oficinas locais com os atores envolvidos. De acordo com Lee, Middleton e Phillips (2003), um dos passos para o envolvimento da população 
é decidir em conjunto, sendo que isso ocorre quando as pessoas afetadas por uma questão são convidadas a aprender sobre ela, discutir e tornar-se parte do processo de tomada de decisão final. Nesta etapa foi utilizado o método ZOPP, concebido no final da década de 70 e início dos anos 80 pela Agência Alemã de Cooperação Técnica (GTZ - Gesellschaft für technische Zusammenarbeit), sendo realizadas dinâmicas e instrumentos voltados à facilitação do processo participativo, conforme Moraes e Pires (2006). Entre as técnicas foram utilizadas tempestade de ideias, trabalho visualizado e discussão em grupo, orientadas pelo moderador, considerado agente facilitador.

Etapa 3 - Elaboração de Listagem de Problemas e de Oportunidades observados em cada curso de atuação. Contou-se com o método de observação participante (SEIXAS, 2005), estabelecendo uma escala de valores que variou em Baixa, Média e Alta intensidade.

Etapa 4 - Estabelecimento de medidas para eliminação e/ou minimização dos Entraves, sendo realizado por meio da hierarquização, da relevância e da problemática.

Etapa 5 - Instituiu-se medidas para potencializar as oportunidades, sendo hierarquizadas segundo as possibilidades de sucesso.

As etapas 4 e 5 serão desenvolvidas posteriormente, sendo também repensado, nos novos processos, o uso de metodologias recomendadas pela IUCN, bem como considerar os diferentes níveis de participação, entre as modalidades: Informação, Consulta, Decisão em Conjunto e Apoio Independente dos Interesses Comunitários, sendo este o mais elevado nível (LEE; MIDDLETON; PHILLIPS, 2003).

\section{Resultados}

Foram trabalhados oito processos de unidades de conservação, os quais: Parques
Naturais Municipais (PNM) do Atalaia e da Ressacada, Área de Proteção Ambiental (APA) do Brilhante, Costa Brava e Morro do Gavião e Unidades de Conservação (UC) Morraria da Praia Vermelha e Morro dos Anjos (categorias a definir, mas com tendência a Uso Sustentável), e Lagoa Quincaludo (apontado em estudo como Parque Natural Municipal), sendo que no Quadro 1 podem ser verificadas informações resumidas sobre os mesmos.

As técnicas e estratégias utilizadas em cada processo variaram de acordo com as características dos mesmos e a fase em que se encontravam.

Os diversos processos atuaram em cinco (5) municípios da região centro-norte catarinense e tiveram trinta e cinco (35) instituições envolvidas entre órgãos públicos, organizações não governamentais e instituição de ensino, assim como dezoito (18) estudantes participatantes, sendo dois (2) bolsistas diretos com o projeto, além de vários representantes da comunidade que participaram em diferentes momentos.

Foi possível verificar um maior investimento de atividades e maior envolvimento de atores sociais no processo do PNM do Atalaia, possivelmente por este ter sido resultado de medida compensatória de licenciamento ambiental que envolveu diferentes segmentos da sociedade atuando com certa pressão política.

Nos Quadros 2 e 3 podem ser verificadas listagens de problemas e de oportunidades, respectivamente, observados durante o desenvolvimento dos diferentes processos, conforme escala de valores de intensidade.

Os casos de "Ausência de Decisão Política" considerados com intensidade Média se deram: 1) PNM do Atalaia pelo fato do Parque haver sido criado durante o período de atuação deste trabalho, assim como a elaboração de seu Plano de Manejo, mesmo que por imposição do órgão ambiental estadual licenciador (processo de medida compensatória) e mesmo que nenhuma 
QUADRO 1 - RESUMO DE INFORMAÇÕES SOBRE OS PROCESSOS DE IMPLANTAÇÃO DE UNIDADES DE CONSERVAÇÃO, 2007

\begin{tabular}{|c|c|c|c|}
\hline $\begin{array}{c}\text { Unidade de } \\
\text { Conservação }\end{array}$ & $\begin{array}{l}\text { Localização e } \\
\text { Condição Atual }\end{array}$ & Atividades & Atores Envolvidos \\
\hline PNM do Atalaia & $\begin{array}{c}\text { Itajaí } \\
\text { Criado, não } \\
\text { implantado e com } \\
\text { Plano de Manejo } \\
\text { a ser aprovado }\end{array}$ & $\begin{array}{l}\text { 1) Consolidação do plano de } \\
\text { manejo; } \\
\text { 2) Apresentação oral em } \\
\text { audiência pública para criação } \\
\text { do Parque; } \\
\text { 3) Reuniões e Oficinas } \\
\text { participativas } \\
\text { 4) Criação do Conselho Gestor }\end{array}$ & $\begin{array}{l}1 \text { Prefeitura Municipal, Câmara } \\
\text { de Vereadores; } 5 \text { órgãos públicos } \\
\text { municipais, } 3 \text { órgãos públicos } \\
\text { estaduais, } 7 \text { organizações não } \\
\text { governamentais, } 1 \text { universidade, } \\
10 \text { estudantes, representantes da } \\
\text { comunidade }\end{array}$ \\
\hline $\begin{array}{c}\text { PNM da } \\
\text { Ressacada }\end{array}$ & $\begin{array}{c}\text { Itajaí } \\
\text { Criado, não } \\
\text { implantado e nem } \\
\text { definidos seus } \\
\text { limites }\end{array}$ & $\begin{array}{l}\text { 1) Estudo de delimitação do } \\
\text { Parque; } \\
\text { 2) Aprovação de Projeto de } \\
\text { pesquisa "Levantamento de } \\
\text { vegetação para definição dos } \\
\text { limites do parque"; } \\
\text { 3) Palestra sobre o Parque; } \\
\text { 4) Reuniões e oficinas } \\
\text { participativas }\end{array}$ & $\begin{array}{l}\text { Câmara de Vereadores, } 3 \text { órgãos } \\
\text { públicos municipais, } 1 \text { órgão } \\
\text { público estadual, } 3 \text { organizações } \\
\text { não governamentais, } 7 \text { estudantes, } \\
1 \text { universidade, } 1 \text { escola pública, } \\
\text { representantes da comunidade }\end{array}$ \\
\hline APA do Brilhante & $\begin{array}{c}\text { Itajaí } \\
\text { Criado, não } \\
\text { implantado e nem } \\
\text { definidos seus } \\
\text { limites } \\
\end{array}$ & $\begin{array}{l}\text { 1) Entrevistas; } \\
\text { 2) Orientação de pesquisa sobre } \\
\text { Sistema Agroflorestal; } \\
\text { 2) Banco de dados sobre } \\
\text { cadastramento de propriedades }\end{array}$ & $\begin{array}{l}3 \text { órgãos públicos, } 2 \text { organizações } \\
\text { não governamentais, } 3 \text { estudantes, } 1 \\
\text { universidade }\end{array}$ \\
\hline APA Costa Brava & $\begin{array}{l}\text { Bal. Camboríu } \\
\text { Criado, não } \\
\text { implantado e com } \\
\text { Plano de Manejo } \\
\text { a ser aprovado }\end{array}$ & $\begin{array}{l}\text { 1) Parecer técnico sobre } \\
\text { proposta sobre APA no Plano } \\
\text { Diretor; } \\
\text { 2) Palestra em audiência pública } \\
\text { sobre a APA }\end{array}$ & $\begin{array}{l}\text { Cãmara de vereadores, } 1 \text { órgão } \\
\text { público municipal, } 5 \text { organizações não } \\
\text { governamentais, } 1 \text { universidade, } 2 \\
\text { estudantes }\end{array}$ \\
\hline $\begin{array}{l}\text { APA Morro do } \\
\text { Gavião }\end{array}$ & $\begin{array}{l}\text { Camboriú } \\
\text { Criado, não } \\
\text { implantado e não } \\
\text { definidos seus } \\
\text { limites } \\
\end{array}$ & $\begin{array}{l}\text { 1) Parecer técnico sobre } \\
\text { proposta de efetivação da APA; } \\
\text { 2) Reunião }\end{array}$ & $\begin{array}{l}1 \text { órgão público municipal, } 1 \text { órgão } \\
\text { público estadual, } 3 \text { organizações não } \\
\text { governamentais, } 1 \text { universidade, } 1 \\
\text { estudante }\end{array}$ \\
\hline $\begin{array}{l}\text { UC Lagoa } \\
\text { Quincaludo }\end{array}$ & $\begin{array}{c}\text { Penha } \\
\text { Não decretado, } \\
\text { mas apontado } \\
\text { como Parque } \\
\text { Natural Municipal } \\
\end{array}$ & $\begin{array}{l}\text { 1) Entrevista com a } \\
\text { comunidade; } \\
\text { 2) Diagnóstico ambiental como } \\
\text { subsídio à implantação de UC }\end{array}$ & $\begin{array}{l}\text { Prefeitura Municipal, } 3 \text { organizações } \\
\text { não governamentais, } 4 \text { estudantes, } \\
1 \text { universidade, representantes da } \\
\text { comunidade }\end{array}$ \\
\hline $\begin{array}{l}\text { UC Praia } \\
\text { Vermelha }\end{array}$ & $\begin{array}{c}\text { Penha } \\
\text { Não decretado }\end{array}$ & $\begin{array}{l}\text { 1) Encaminhamento de } \\
\text { proposta de estudo de } \\
\text { viabilidade de UC; } \\
\text { 2) Reuniões e oficinas } \\
\text { participativas }\end{array}$ & $\begin{array}{l}1 \text { organização não governamental, } 1 \\
\text { universidade }\end{array}$ \\
\hline $\begin{array}{l}\text { UC Morro dos } \\
\text { Anjos }\end{array}$ & $\begin{array}{c}\text { Porto Belo } \\
\text { Não decretado }\end{array}$ & $\begin{array}{l}\text { 1) Diagnóstico ambiental como } \\
\text { subsídio à implantação de UC; } \\
\text { 2) Reuniões }\end{array}$ & $\begin{array}{l}1 \text { organização não governamental, } 1 \\
\text { universidade }\end{array}$ \\
\hline
\end{tabular}


QUADRO 2 - PRINCIPAIS PROBLEMAS OBSERVADOS NOS PROCESSOS DE IMPLANTAÇÃO DE UNIDADES DE CONSERVAÇÃO, 2007

\begin{tabular}{|c|c|c|c|c|}
\hline $\begin{array}{c}\text { Unidade de } \\
\text { Conservação }\end{array}$ & $\begin{array}{c}\text { Ausência de Decisão } \\
\text { Política }\end{array}$ & $\begin{array}{c}\text { Ausência de } \\
\text { Recursos Financeiros }\end{array}$ & $\begin{array}{c}\text { Carência de } \\
\text { Informação e/ou } \\
\text { Conscientização }\end{array}$ & $\begin{array}{c}\text { Carência de } \\
\text { Mobilização Social }\end{array}$ \\
\hline PNM do Atalaia & Média & Baixa & Média & Baixa \\
\hline PNM da Ressacada & Alta & Alta & Média & Média \\
\hline APA do Brilhante & Alta & Alta & Média & Média \\
\hline APA Costa Brava & Média & Média & Média & Baixa \\
\hline $\begin{array}{c}\text { APA Morro do } \\
\text { Gavião }\end{array}$ & Média & Alta & Alta & Baixa \\
\hline $\begin{array}{c}\text { UC Lagoa } \\
\text { Quincaludo }\end{array}$ & Alta & Alta & Alta & Média \\
\hline UC Praia Vermelha & Alta & Alta & Média & Baixa \\
\hline UC Morro dos Anjos & Alta & Alta & Alta & \\
\hline
\end{tabular}

QUADRO 3 - PRINCIPAIS OPORTUNIDADES OBSERVADAS NOS PROCESSOS DE IMPLANTAÇÃO DE UNIDADES DE CONSERVAÇÃO, 2007

\begin{tabular}{|c|c|c|c|c|}
\hline $\begin{array}{c}\text { Unidade de } \\
\text { Conservação }\end{array}$ & $\begin{array}{c}\text { Riqueza de } \\
\text { Rec. Naturais/ } \\
\text { Biodiversidade }\end{array}$ & $\begin{array}{c}\text { Existência de Beleza } \\
\text { Cênica }\end{array}$ & $\begin{array}{c}\text { Interesses da } \\
\text { População }\end{array}$ & Poucos Conflitos \\
\hline PNM do Atalaia & Alta & Alta & Alta & Média \\
\hline PNM da Ressacada & Alta & Média & Média & Baixa \\
\hline APA do Brilhante & Alta & Média & Baixa & Média \\
\hline APA Costa Brava & Alta & Alta & Média & Média \\
\hline $\begin{array}{c}\text { APA Morro do } \\
\text { Gavião }\end{array}$ & Alta & Média & Média & Alta \\
\hline $\begin{array}{c}\text { UC Lagoa } \\
\text { Quincaludo }\end{array}$ & Média & Média & Alta & \\
\hline UC Praia Vermelha & Alta & Alta & Média & Média \\
\hline UC Morro dos Anjos & Média & Média & Média & Média \\
\hline
\end{tabular}

NOTA: Considerando as UCs Praia Vermelha e Morro dos Anjos (a definir) como unidades de Uso Sustentável, possivelmente APAs, em que não sejam necessárias desapropriações, e Lagoa Qincaludo como Parque.

medida contida no plano tenha sido efetivada; 2) APA Costa Brava devido haver desenvolvido Plano de Manejo, apesar de que o mesmo foi imposto pelo ministério público federal, assim como não tendo sido desenvolvido e aprovado segundo participação comunitária; 3) APA Morro do Gavião, considerando a iniciativa da Secretaria Municipal de Meio Ambiente em retomar o processo, mesmo que ainda de forma incipiente.
Da mesma forma, a problemática "Ausência de Recursos Financeiros" com intensidade baixa para o PNM do Atalaia e média para a APA Costa Brava foi decorrente de investimentos impostos por instituições externas às responsáveis pela administração das unidades.

Para Loureiro, Azaziel e Franca (2003), o cidadão é estimulado a participar como gestor do espaço de vida, ao ter oportunidade 
da apropriação democrática do ambiente $e$ da identificação da sua base territorial, e ao compreender a dinâmica dos ecossistemas e das causas estruturantes dos problemas. Portanto, o aporte de informações e de vivências pode permitir maior envolvimento com o lugar e estímulo à participação nos processos de conservação. A intensidade média para a "Carência de Informação e/ou Conscientização" teve como base o fato de já existirem estudos sobre algumas áreas em questão. Porém, não necessariamente vinculada a divulgação dos mesmos ao público necessário, no caso, a população local, e não garantindo o efeito de conscientização, que também se soma ao sentimento de afetividade.

Em relação à "Carência de Mobilização Social", foi observada intensidade média e baixa, ou seja, não são problemas de intensidade alta, considerando que existe certa legimidade de atores sociais envolvidos nos variados processos, mas sem sugerir uma representatividade em número de participantes.

Considerando que o principal objetivo da categoria Parque é a proteção do ecossistema, a "Riqueza de Recursos Naturais/Biodiversidade" (Quadro 3) foi considerada como oportunidade à efetivação das UCs, principalmente em relação à integridade e representatividade. Neste quesito, apenas as UCs Lagoa Quincaludo e Morro dos Anjos apresentaram intensidade de oportunidade média, em função de alterações antrópicas, somada a pequena extensão de área da primeira.

A "Beleza Cênica" é uma característica que justifica a categoria Parque, e mesmo com certo caráter de subjetividade, a presença de água e de vegetação, associada à complexidade topográfica e a naturalidade denotam elementos nas preferências paisagísticas (MARENZI, 1996). Correspondem a estas características, o PNM do Atalaia, a APA Costa Brava e UC Praia Vermelha. As outras áreas apresentaram esta oportunidade com média intensidade, considerando o conjunto paisagístico, mas todas apresentam pontos singulares de atrativo valor cênico.

Para Costa (1997), o envolvimento da comunidade é de total importância, pois sem o entendimento, o apoio, a participação e a colaboração da população nenhum projeto tem sustentabilidade. Desta forma, o "Interesse da População" foi um potencial de oportunidade contemplado, sendo destacado com alta intensidade o PNM do Atalaia, possivelmente resultado do planejamento participativo ocorrido na ocasião da elaboração do Plano de Manejo, que buscou despertar o interesse comunitário. Neste caso, o interesse da população foi demonstrado pela insatisfação de haver sido decretado apenas uma parte da morraria como Parque. No processo da UC Lagoa Quincaludo é ressaltado o fato de que a área apresenta significativo impacto decorrente do aporte de resíduos de esgoto doméstico, que afeta a população do entorno pelo odor na área, assim como a mesma estar localizada próximo ao portal de entrada da cidade de Penha.

Os conflitos nos processos de UC podem ser inúmeros, mas um dos mais relevantes se dá em decorrência da necessidade de desapropriações e/ou a falta de recursos financeiros para as mesmas. Com base nisto, foi observado que o fato de existirem "Poucos Conflitos" denota uma oportunidade para a implantação das UCs consideradas, destancando a UC Lagoa Quincaludo em que basicamente não haverá necessidade de desapropriações, pois a maior área de interesse é a de preservação permanente (lagoa e mangue) com mínima ocupação, por isso com intensidade de oportunidade alta. No caso do PNM do Atalaia, mesmo existindo recursos para desapropriações, o mesmo foi insuficiente para a aquisição de área de interesse da população, o que ocasionou a redução da intensidade da oportunidade para média. As outras UCs também tiveram esta intensidade de oportunidade, com exceção do PNM da Ressacada, cujas expectativas de 
conflitos são inúmeras, considerando que a maioria dos imóveis que contemplam a proposta de limites do Parque são áreas particulares, cujo aporte de investimentos financeiros deverá ser muito significativo.

\section{Considerações finais}

O Projeto de extensão "Apoio à implantação de Unidades de Conservação na região centro-norte catarinense" tem atuado com diferentes demandas, envolvendo diferentes atores sociais e estratégias de ação, em cinco municípios e oito processos, sendo dois de Parques Naturais Municipais, três de Áreas de Proteção Ambiental Municipais e três de UCs, ainda a serem criadas. No entanto, mesmo as unidades já criadas carecem de implantação e até de definição de limites. Fato que denota a necessidade de prosseguimento de capacitação, de acompanhamento e de estímulo aos processos, de maneira que os mesmos se efetivem e se tornem auto-sustentáveis no sentido de manejo. Também é importante considerar a necessidade de avaliação permanente do processo, conforme indica Phillips (2000).

A intensidade de esforços deverá se dar de maneira diferente nos variados processos, considerando que alguns já se encontram mais adiantados que outros, mas decorrente da imposição de setores que não a responsabilidade pela administração das UCs.

De maneira geral é possível destacar que o problema de maior entrave nos processos de UCs se refere à ausência de decisão política, a qual uma vez solucionada pode surgir efeitos positivos, reduzindo outros problemas, pois estes estão relacionados. No entanto, a resposta para a solução deste principal problema depende também da pressão da população, que é decorrente da informação (capacitação) e da conscientização da mesma, vinculada à mobilização social. Por outro lado, as oportunidades existentes nos processos é que os alimenta no sentido de justificativa para esforços no sentido de investimentos e de ações voltadas a efetivação dos processos.

A vivência nos diferentes processos possibilitou a observação de problemas e de oportunidades à implantação e efetivação das unidades de conservação, reduzindo a subjetividade de resultados. A organização $e$ a sintetização destes pontos negativos, como entraves, e positivos, como facilitadores, podem contribuir para a nova etapa, no sentido de buscar minimizar os problemas e intensificar as oportunidades, direcionando as estratégias a serem utilizadas.

Portanto, considerando que os processos referentes à UCs são permanentes, flexíveis e devem ser sempre participativos, é possível afirmar que estes que fizeram parte desse Projeto de Extensão, período 2007, ainda se encontram em fase incipiente e imatura. A fim de resultados mais eficientes e consolidados há necessidade de sua continuidade como forma de enriquecimento e de retro-alimentação, possibilitados pela análise de resultados desse trabalho, a qual pode ser considerada como um meio de avaliação. 


\section{REFERÊNCIAS}

BRASIL. Lei n. 9.985 - 18 jul. 2000. Instituiu o Sistema Nacional de Unidades de Conservação. Brasília, 2000.

BRITO, M. C. W. Unidades de Conservação - intenções e resultados. 2 ed. São Paulo: Annablume, 2003. 230p.

COSTA, J. P. O. Avaliação da Reserva da Biosfera da Mata Atlântica. Série Cadernos da Reserva da Biosfera, n. 6, São Paulo, 1997.

LEE, T.; MIDDLETON, J.; PHILLIPS, A. Guidelines for management planning of protected areas. Suiça: IUCN/ Cardiff University, 2003.

LOUREIRO, C. F. B.; AZAZIEL, M.; FRANCA, N. Educação Ambiental e Gestão Participativa em Unidades de Conservação. Rio de Janeiro: IBASE/IBAMA, 2003. 44p.

MARENZI, R. C. Estudo da valoração da paisagem e preferências paisagísticas no município da Penha - SC. 119 p. Dissertação (Mestrado em Conservação da Natureza) - Setor de Ciências Agrárias, Universidade Federal do Paraná, Curitiba, 1996.
; FRIGO, F; ECCEL, R.; SCHIMIDT, A. D. Unidades de Conservação de Santa Catarina: Base preliminar de um diagnóstico de situação. In: SIMPÓSIO DE ÁREAS PROTEGIDAS, III. Anais... Pelotas, 2005, p. 26-34.

MORAES, W. B. C.; PIRES, R. D'A. Planejamento participativo. Disponível em: <http://www.participando.com.br>. Acesso em: 17 nov. 2006.

PHILLIPS, A. Evaluating Effectiveness. Suiça: IUCN/ Cardiff University, 2000.

SANTA CATARINA. Lei $n^{\circ} 11.986$ - 12 nov. 2001. Instituiu o Sistema Estadual de Unidades de Conservação. Florianópolis, 2001.

SEIXAS, Cristina. S. 2005. Abordagens e técnicas de pesquisa participativa em gestão de recursos naturais. In. VIEIRA, Paulo Freire; BERKES, F; SEIXAS, Cristina. S (Orgs.). Gestão integrada e participativa dos recursos naturais. Florianópolis: Secco/APED, p. 73-105, 2005.

Texto recebido em 20 de março de 2009. Texto aprovado em 31 de março de 2009. 